\title{
The EUROSON Congress 2020 takes place in Bergen from June 11.-13. 2020
}

We have received a total of 195 abstracts and case reports until the end of the deadline on February $29^{\text {th }}$. This is a very high number ant it exceeds our expectations! The review process will now start and the Scientific Committee as well as committee leaders from EFSUMB are now starting on reviewing and selecting the abstracts for oral presentation or poster presentation. We have a limited number of slots for oral presentations, but we plan to have abstract presentations as part of several of the sessions, following invited lectures. The oral abstract presentations will be organized so they fit with the topic of the session they appear in. We also plan to exhibit posters in a central place in the congress venue, and to have selected abstracts presented in speed-poster presentations during breaks.

We truly thank all the authors for their valuable input to the Conference. Presenting new research and interesting case reports adds valuable content and makes the conference even more up-to-date on several topics.

\section{Interventional Ultrasound}

Ultrasound is a real time imaging method which makes it particularly useful for guiding interventional procedures. Over two sessions on Saturday June 13. Some of the most experienced interventional sonsographers will present useful topics. We will learn more about US guided Ablation presented by Liat Appelbaum from Israel. Torben Lorentzen from Denmark wil show how we can use US in order to place a percutaneous gastroenterostomy. Zeno Sparchez from Romania will present how he performs Contrast enhanced US guided biopsies of large retroperitoneal and renal masses. After the break Christian Nolsøe from Denmark will present how US can be part of staging of cancer and for guiding ablation of metastases. Following this Carla Serra from Italy will focus on Liver HCC/Met RFA treatment and follow-up. As complications may occur in interventional US this is important to have knowledge about, and Zeno Sparchez will focus on this topic. Finally Boris Brkljacic from Croatia will share his experience on US guided breast ablations. This will be interesting for everyone who are interested in interventional US or want to enter this very useful field of US.

\section{New! Course on Interventional US with Hands-on practice on phantoms}

We are now planning a one day course in interventional US focusing on percutaneous tissue sampling, drainage, using Seldinger technique for placing catheteters etc. Sara Sehlstedt, Interventional Radiologist from Sweden has long experience in teaching this and will be organizing this one day course on Thursday, June 11. The course is available to all registrants, but we there will be a separate registration on the homepage when the program is ready, and the hands-on part will have limited places. First come, first serve.

\section{Postgraduate Course: Liver Elastography}

Are you curious about liver elastography or eager to improve your knowledge and practice? 
The Postgraduate Course takes place on Friday, June 12, in liver elastography is a course aimed both at those who are inexperienced and want to learn more about the method and experienced users who want to update their knowledge and improve their practical skills.

Liver elastography is established as an important clinical tool for assessment of liver fibrosis and prognosis in the diagnosis and follow-up of patients with chronic liver diseases. The field is rapidly evolving: new modalities and new indications for the use of liver elastography are emerging. The course has a limited number of 60 .

\section{Muscloskeletal US: Shoulder}

Shoulder pain is common, and it is difficult to find the correct causes by use only of clinical examinations. Ultrasound has been shown to give a major contribution to the diagnosis of several forms of pathologies causing pain and reduced function of the shoulder. Thus, knowledge of how to perform the optimal ultrasound examination of the shoulder is highly important for the clinicians for their diagnosis and treatment of patients with different forms of shoulder pathology.

Marnix van Holsbeeck is the director of musculoskeletal radiology in the Department of Radiology and director of radiology in the Department of Orthopaedic Surgery at the Henry Ford Health System. He is an authority in the field of musculoskeletal radiology, writing a large number of articles in the field of MSUS and is the first author for a leading radiology textbook; Musculoskeletal Ultrasound. Holsbeeck will give lectures on shoulder ultrasound including different pathologies and he will have live ultrasound demonstration on models.

We have Norwegians to teach on different shoulder pathologies; Tore Prestgaard, specialist in physical medicine (Kysthospitalet, Stavern) will talk on the important topic of capsulitis of the shoulder, Stephan Moosmaier, orthopaedic surgeon (Martina Hansens Hospital, Bærum) will teach on the topic calcifications of the shoulder and Herlof Harstad, specialist in physical medicine (Kysthospitalet, Stavern) will talk om the

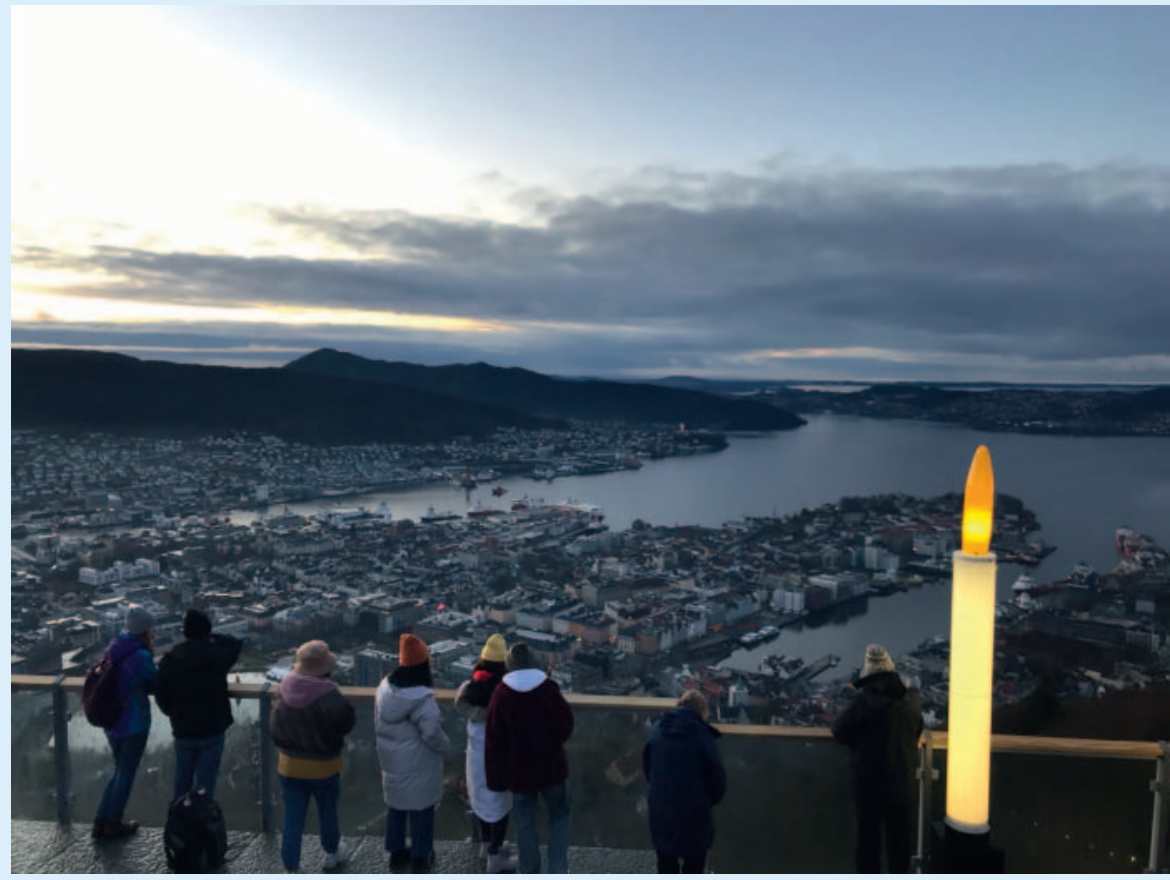

Winter moods in Bergen from Mount Fløyen. We are waiting for you!

axillary and suprascapular nerve. In addition, orthopaedic surgeon Kirsten Lundgreen (Lovisenberg Diakonale Sykehus, Oslo) will talk on the subacromial pain syndrome.

\section{Obstetrics: Follow up of malformations}

As screenings and predictive medicine develop, it is important to address the psychological distress and anxiety associated with the finding of an anomaly. The detection of a fetal malformation on ultrasound also put clinicians and pregnant women in difficult and precarious situations.

What information and how it is communicated is crucial to parent's decision-making about continuing or terminating a pregnancy. Not enough is known about how highrisk women and their partners cope while waiting for diagnostic results. Associate professor Anne Kaasen at the Faculty of Health Sciences Department of Nursing and Health Promotion at Oslo Met will present her extensive research in stress in parents after detection of a fetal anomaly.

Stina Lou, senior research scientist at DEFACTUM, Central Denmark Region and
Center for Fetal Diagnostics, Aarhus University Hospital, has a MA in anthropology and a $\mathrm{PhD}$ in medicine. Her research is within pregnancy and prenatal diagnosis, aspects of clinical communication, risk perception and the experiences and concerns of pregnant couples.

The session is essential for all levels in the field of obstetrics and gynecology, reproductive and fetal medicine.

\section{Obstetrics: Ultrasound assessment of the umbilical cord}

A normal development of the umbilical cord is crucial for a successful outcome of pregnancy, and an abnormal cord may be an indicator for increased risk. There is an increased awareness for umbilical cord accidents as it contributes substantially to intrauterine deaths. Dr C. Ebbing is a senior consultant at the fetal medicine section, Department of obstetrics and gynecology and an assistant professor at the University of Bergen. Through epidemiology research based on data from the Medical Birth Registry of Norway and clinical research, she has focused on the cord and placenta, and associations to adverse outcome. She will give 
an overview of the theme to raise awareness, and will demonstrate how to examine the cord and placenta by ultrasound.

This session will also include presentation of submitted abstracts

\section{Postgraduate Course: Liver Elastography}

Are you curious about liver elastography or eager to improve your knowledge and practice?

The Postgraduate Course in liver elastography is a course aimed both at those who are inexperienced and want to learn more about the method and experienced users who want to update their knowledge and improve their practical skills.

Liver elastography is established as an important clinical tool for assessment of liver fibrosis and prognosis in the diagnosis and follow-up of patients with chronic liver diseases. The field is rapidly evolving: new modalities and new indications for the use of liver elastography are emerging.

This postgraduate course provides an overview of the basic principles and pitfalls of the spectrum of elastography modalities given by Fabio Piscaglia, known as a brilliant lecturer and world leading expert in ultrasound and liver elastography. This is followed by presentations by leading researchers in the field regarding the use of liver elastography in various liver diseases, from viral hepatitis to alcoholic or non-alcoholic liver disease and in portal hypertension. Professor Christoph Dietrich, previous EFSUMB president, will make theory come to life in his live demonstration of liver elastography, sharing his tricks for tricky patients. Eager to try it out yourself? There will be ample time for hands-on training with demonstration of various modalities and platforms.

\section{Montana Family \& Youth Hostel}

If you are traveling on a budget, the Montana Family \& Youth Hostel is a great option.

It is located in beautiful surroundings up the hillside of Mount Ulriken, about $5 \mathrm{~km}$ south of Bergen City Centre, with good bus connections.

If you buy the "Bergen Card", you travel "free" and have free access to most of the many tourist attractions in Bergen.

http://www.montana.no/en/

Please note that bed linen is not included.

Rental: NOK 50

For booking please contact bergen.monta na@hihostels.no and provide the following reference: EUROSON 